\title{
ANÁLISE VISUAL EM CORPOS DE PROVA CONFORMADOS POR PRENSAGEM DE CERÂMICA BRANCA COM ADIÇÃO DE RESÍDUOS
}

\author{
Karoline de Lourdes Monteiro Guimarães \\ Universidade Ceuma \\ kgguimaraes@hotmail.com \\ Denilson Moreira Santos \\ Universidade Federal do Maranhão \\ denilson@ufma.br
}

Resumo: O estudo tecnológico de materiais provenientes da mistura de massa cerâmica branca com resíduos tem sido observado na literatura científica nos últimos anos, traçando suas propriedades e características. Contudo, avaliar seu aspecto estético também corresponde a algo relevante no desempenho do material. Assim, esta pesquisa realizou uma análise visual em método adaptado da NBR 13.818/ 1997 acerca da variação tonal e contabilização de problemas superficiais em corpos de prova de cerâmica branca com ossos bovinos e em outro momento com fino de rochas, conformados por prensagem, de modo comparativo à triaxial. Os resultados mostraram que as composições com 30 \% e 35\% de resíduos apresentaram uma melhor qualidade visual em ambos os resíduos.

Palavras-chave: materiais, cerâmica branca, análise visual, ossos bovinos, fino de rochas.

\begin{abstract}
The technological studies about materials from the mixed of white ceramic with waste has been noted in the scientific literature in recente years, setting their proprieties and characteristics. However, assessing it is aesthetic aspect also corresponds to something relevant in the performance of the material. So, this research conducted a visual analysis method adapted by NBR 13.8181/ 1997 about the tonal variation and accounting superficial problems in white ceramic specimens with cattle bones and at another time with draff rocks, shaped by pressing, so comparative by the triaxial. The results show that the compositions with $30 \%$ and $35 \%$ of waste had a better visual quality in both residues.
\end{abstract}

Key-words: materials, white ceramic, visual analysis, cattle bones, draff rocks. 


\section{INTRODUÇÃO}

Ao falar em cerâmica, pensa-se imediatamente em produtos utilitários artesanais, contudo este assunto envolve um universo maior e mais rico. Nos últimos anos, pesquisadores têm desenvolvido projetos com alta tecnologia para aplicação na engenharia, medicina, indústria aeroespacial e eletrônica (SHACKELFORD, 2008), desconstruindo esta visão limitada de sua utilização. Assim, estudar e propor de novas composições de massas cerâmicas ganha relevância para o avanço tecnológico.

Neste contexto, realizou-se um estudo de materiais constituídos pela mistura de resíduos provenientes de outros processos e cerâmica branca da região de Mirinzal (Maranhão), em uma análise de características estéticas, em método adaptado da NBR 13.818/1997 (ABNT, 1997). Dessa forma foi possível identificar diferenças tonais e problemas superficiais em corpos de provas conformados por prensagem.

Outros trabalhos são encontrados acerca da caracterização tecnológicas destes dois materiais, contudo a análise visual não foi identificada em nenhuma pesquisa consultada. Assim, busca-se contribuir como referencial teórico para estudos posteriores que abordem a qualidade estética de materiais cerâmicos com resíduos.

Algo interessante foi perceber que resíduos distintos podem gerar resultados bem diferentes quando adicionados a um mesmo material, ressaltando o cuidado na escolha da matéria-prima de um produto. Além disso, observou-se ser possível indicar a qualidade visual de um material por meio de dados numéricos.

Para conhecer os materiais desta pesquisa, faz-se necessário a conceituação e a caracterização da cerâmica branca e dos resíduos, descritos nos tópicos seguintes.

\section{CERÂMICA BRANCA}

A cerâmica branca pode ser classificada quanto à sua coloração, onde as mais conhecidas são as cerâmicas vermelhas e as brancas. A vermelha apresenta tons terrosos após queima, entre amarelo queimado, marrom e vermelho, devido ao óxido de ferro. Já as brancas, com baixo teor do óxido, tem tonalidades entre roseado, creme e branco, além de grãos finos. Sua principal matéria-prima é a argila branca, também chamada de argila preta, por apresentar cor escura ao ser extraída.

Segundo Norton (1973, p. 168), as massas mais usuais da cerâmica branca são as triaxiais, formadas pela mistura de três matérias-primas: a argila plástica rica em caulim, o feldspato e o quartzo. Portanto, são chamadas de triaxiais tradicionais.

O feldspato é capaz de baixar a temperatura de fusão molecular e formação da fase vítrea cerâmica. Portanto, é um fundente que gera maior resistência, tenacidade e durabilidade (ALATRISTA, 2008, p. 10). Quando em excesso, pode gerar instabilidade dimensional e defeitos, por isso deve ser bem quantificado.

Os caulins, também chamados de china clays, correspondem a um material argiloso de pouca plasticidade e baixa resistência mecânica, composto por caulinita e/ou haloisita, com temperatura de queima em torno de $1200^{\circ} \mathrm{C}$ (SANTOS, 1975 , p. 468). Já as argilas plásticas, são constituídas por finas partículas de caulinita, mica (ilita) e quartzo. São utilizadas na massa cerâmica para aumentar a plasticidade, quando misturadas à água, e para elevar a resistência mecânica (NORTON, 1973, p. 31).

No Maranhão, há pontos de extração de argilas plásticas para cerâmica vermelha, como mostra a Figura 1. Em todo o Estado há produtores, com principais polos em Itapecuru Mirim, Timon, Caxias e Imperatriz (MELLO et al, 2011, p. 25). 


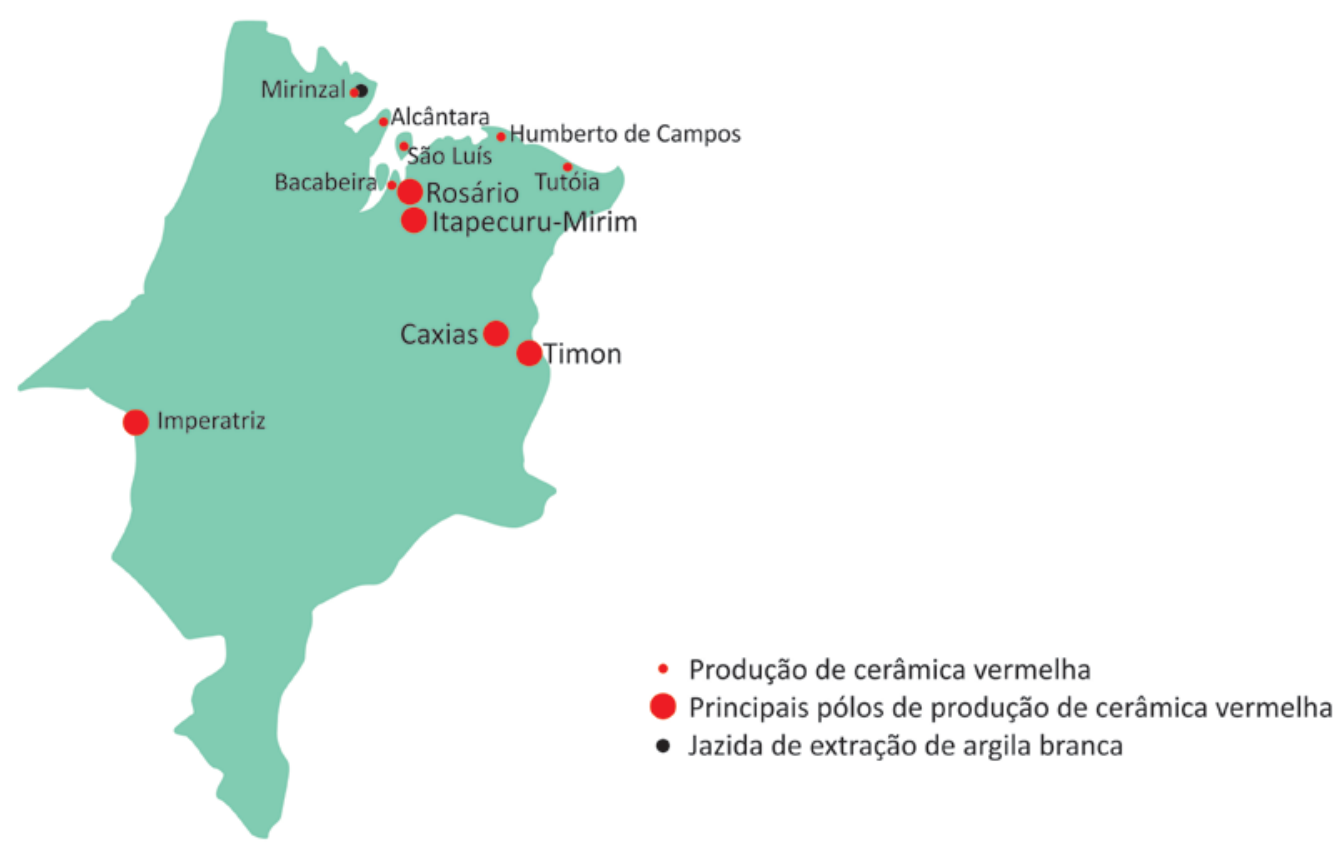

Figura 1: Locais de produção cerâmica no Maranhão.

Fonte: Elaborado pelo autor, com base na pesquisa realizada.

Existem reservas de argila para cerâmica branca no Estado, porém pouco exploradas (MELLO et al, 2011, p. 25), como na Baixada Maranhense, em Mirinzal (Fig. 1), utilizada nesta pesquisa. Estudos de caracterização de propriedades físico-químicas (MOREIRA et al, 2012) mostram que a argila desta região possui alto teor de caulinita e alumínio propiciando tons claros, elevada plasticidade e baixa resistência mecânica.

De modo geral, há uma problemática no uso das argilas, uma vez que podem apresentar características variadas conforme local de extração, tipologia e matériasprimas envolvidas. Em uma mesma jazida é possível encontrar muitos tipos de materiais argilosos, de constituição variável, assim há irregularidade na composição. Até um mesmo tipo de argila pode apresentar características diferentes. Isto acontece por ser um material natural, produto de diferentes formações geológicas e das interferências de intempéries. Isto inviabiliza precisão técnica, como em outros materiais, porém é possível submetê-lo a análises, traçando previsões de desempenho.

\section{RESÍDUOS}

Dentro do assunto, estudos sugerem o aproveitamento de resíduos em novos processos e materiais, inclusive para produtos cerâmicos, contudo vale frisar que nem todos os resíduos podem ser utilizados para esta finalidade devido à etapa de queima, que interfere diretamente na estrutura do material, por isso os resíduos não devem liberar gases tóxicos na queima (BRAGANÇA; BERGMANN, 2006), ressaltando a necessidade de uma seleção prévia. Um modo de saber se há viabilidade de utilização de um resíduo é conhecendo qual seu tipo, classificação e características.

Os objetos deste estudo são os resíduos orgânicos da classe II, relativos aos ossos bovinos, e da classe III, do tipo inertes, correspondente ao fino de rochas ornamentais, conforme classificação de resíduos sólidos pela Associação Brasileira de Normas Técnicas em sua NBR 10004 (ABNT, 2004). Ambos não irão emitir gases ao serem queimados, não alteram a composição química de materiais ao seu redor e não poluem quimicamente o meio ambiente, podendo ser utilizados na indústria cerâmica. 
No Brasil, há a Lei no 12.305 que constitui a Política Nacional de Resíduos Sólidos (PNRS) (BRASIL, 2010), que fala acerca do descarte de resíduos sólidos e propõe uma hierarquia de destinação adequada (Art. 9o). Neste trabalho, a reutilização apresenta-se como melhor destino, hierarquizado como a terceira possibilidade, uma vez que não deixarão de ser gerados e nem é possível o controle da redução, pois são provenientes de processos produtivos de outras indústrias, não cabendo à indústria ceramista o controle. Acredita-se, assim, que os ossos bovinos e o fino de rochas possam ser reinseridos em novos produtos e processos cerâmicos.

\subsection{Ossos bovinos}

Acerca dos ossos bovinos, é importante lembrar que o Brasil encontra-se entre os maiores criadores de gado no mundo, perdendo apenas para a Índia, sobretudo no Mato Grosso, Mato Grosso do Sul, Goiás, São Paulo e Minas Gerais (IBGE, 2013, p.5).

Dentre as sobras do abate, os ossos possuem cálcio e fosfato sob a forma de cristais de hidroxiapatita (MENDES FILHO, 2006, p. 5), considerada uma cerâmica naturalmente encontrada em $30 \%$ a $70 \%$ da massa de ossos e dentes (ASKELAND; WRIGHT, 2014, p. 480). Segundo Mendes Filho (2006), é "bioativa e osteocondutora, possui alta resistência à corrosão e de compressão", contudo possui "baixa ductilidade" e uma densidade relativamente alta. Pode ser utilizada como elemento único ou misturada a outros materiais (RIGO et al, 2007).

A porcelana de ossos pode gerar produtos com alvura, translucidez, fino acabamento, elevada resistência mecânica e superfície menos porosa. Contudo, observou-se que há uma resistência cultural na utilização de ossos como matériaprima. Alguns a chamam de "estranha" e até "bizarra". Acredita-se que a falta de conhecimento das propriedades do material, vantagens econômicas, ambientais e estéticas, além do preconceito contribuem, contudo a inserção deste resíduo na produção cerâmica poderia gerar vantagens, sobretudo pela fácil aquisição no Brasil.

\subsection{Fino de rochas ornamentais}

Outro resíduo utilizado foi proveniente do corte de rochas ornamentais, conhecidas comercialmente como granitos e mármores. No Brasil, sua extração em escala industrial foi iniciada no em 1950. Apenas na década de 80 tornou-se um país exportador, sendo hoje o maior fornecedor para os Estados Unidos (TEIXEIRA; MELO; OLIVEIRA, 2012). Assim, o País exporta para os Estados Unidos, Itália, China e Espanha, com produção sobretudo no sudeste do País (SOUZA et al, 2008). Contudo, ao passo que se eleva a produção, a quantidade de perdas e resíduos também cresce.

Segundo Sousa $(2007$, p. 1), as etapas de um processo produtivo de rochas ornamentais podem gerar perdas em torno de $30 \%$ a $40 \%$ da matéria-prima. Para Frangella e Castro (2009), pode chegar a $60 \%$ na produção de revestimentos. Há sobras em grande quantidade, de diversos tamanhos, além do pó que é armazenado em tanques de água, chamado de fino ou borra, dificilmente são reaproveitados em outros processos, tendo como destino o descarte em lixões ou na natureza.

Neste contexto, estudos foram realizados para a avaliação do desempenho da cerâmica com resíduos incorporados, como de Babisk et al (2012) misturando a rocha metamórfica quartizito ao "bolo" cerâmico de argila vermelha em uma porcentagem de até $40 \%$ e queimadas a $800^{\circ} \mathrm{C}$, ou Prado (2014, p. 50), que adicionou resíduos de 
rochas ornamentais à massa para revestimento cerâmico. Esses estudos apresentaram resultados quanto às propriedades tecnológicas, porém sem realização de uma análise visual. Baseado nisso, acredita-se ser interessante contribuir como referencial teórico em outros estudos a partir da análise da cerâmica branca tanto com a adição de ossos bovinos quanto com o fino de rochas ornamentais na apreciação do aspecto estético.

\section{MATERIAIS E MÉTODOS}

Neste trabalho, foi desenvolvida uma pesquisa experimental com abordagem qualitativa, dividida em etapas de coleta das matérias-primas, beneficiamento de resíduos, mistura, conformação por prensagem, secagem, sinterização e análise visual.

Vale citar que não existe uma norma específica que fale a respeito de métodos de ensaio da cerâmica branca, mas utilizou-se a NBR 13.818/1997 (ABNT, 1997) com adaptações, identificando as irregularidades e defeitos a olho nu.

\subsection{Materiais}

Os materiais utilizados foram o caulim em pó, argila plástica extraída na cidade de Mirinzal (Maranhão), quartzo em pó, feldspato potássico, água e o resíduo beneficiado - ossos bovinos ou fino de rochas - em porcentagens variadas (Tabela 1).

Para a formulação das composições, a quantidade de caulim variou conforme quantidade de resíduo. A soma de caulim com resíduo totalizou $75 \%$ da mistura e as porcentagens trabalhadas foram de $30 \%, 35 \%, 40 \%, 45 \%, 50 \%$ e $55 \%$ de resíduos.

Tabela 1 - Porcentagem proposta para os componentes utilizados nas misturas.

\begin{tabular}{llllllll}
\hline \multicolumn{7}{c}{ Componentes dos corpos de prova } \\
\hline Materiais & Triaxial & Teste \#1 & Teste \#2 & Teste \#3 & Teste \#4 & Teste \#5 & Teste \#6 \\
\hline Resíduo & $0 \%$ & $30 \%$ & $35 \%$ & $40 \%$ & $45 \%$ & $50 \%$ & $55 \%$ \\
\hline Caulim & $40 \%$ & $45 \%$ & $40 \%$ & $35 \%$ & $30 \%$ & $25 \%$ & $20 \%$ \\
\hline Argila & $10 \%$ & $7,5 \%$ & $7,5 \%$ & $7,5 \%$ & $7,5 \%$ & $7,5 \%$ & $7,5 \%$ \\
\hline Quartzo & $25 \%$ & $7,5 \%$ & $7,5 \%$ & $7,5 \%$ & $7,5 \%$ & $7,5 \%$ & $7,5 \%$ \\
\hline Feldspato & $25 \%$ & $10 \%$ & $10 \%$ & $10 \%$ & $10 \%$ & $10 \%$ & $10 \%$ \\
\hline Água & $+15 \%$ & $+18 \%$ & $+18 \%$ & $+18 \%$ & $+18 \%$ & $+18 \%$ & $+18 \%$ \\
\hline
\end{tabular}

Fonte: Elaborado pelo autor, com base na pesquisa realizada.

Foram produzidos corpos de prova com os resíduos e triaxiais. Houve correção de água na cerâmica com ossos e rochas para conformação, pois durante os pré-testes, os corpos com $15 \%$ de água quebraram. Assim, utilizou-se $18 \%$ de água.

Os ossos foram coletados em açougues, lavados com sabão e escova, e secados ao ar livre. Para obtenção do pó, foram calcinados em forno elétrico a $1000^{\circ} \mathrm{C}$, triturados com um moinho tipo martelo e peneirados na 100 mesh. Já o fino de rochas ornamentais foi coletado em marmorarias, com a água sendo extraída ao receber calor ao ar livre. $O$ resultado foi peneirado com a peneira 60 mesh.

\subsection{Métodos}

Dentre os métodos, houveram muitas etapas envolvidas, assim buscou-se seguir roteiros, que na cerâmica branca com ossos consistiu-se de: Aquisição dos ossos em açougues; Limpeza dos ossos; Calcinação; Trituração; Peneiramento; Preparo da mistura com demais componentes; Conformação dos corpos de prova; Secagem (estufa a $110^{\circ} \mathrm{C}$ por 24 horas); Sinterização (em forno elétrico a $1200^{\circ} \mathrm{C}$ ); Análise visual. 
$O$ roteiro com fino de rochas consistiu em: Aquisição do fino em marmorarias; Evaporação da água do fino; Peneiramento; Preparo da mistura; Conformação dos corpos de prova; Secagem $\left(110^{\circ} \mathrm{C}\right.$ por 24 horas); Sinterização $\left(950^{\circ} \mathrm{C}\right)$; Análise visual.

\section{RESULTADOS E DISCUSSÕES}

Os corpos de prova foram produzidos com molde metálico, vaselina líquida como desmoldante e prensa hidráulica, identificados com letras (OB para ossos; R para fino) e números (porcentagem residual adicionada e ordem cronológica de confecção).

Neste trabalho, levou-se em consideração a estética, por isso foi escolhido o método de análise visual, desenvolvendo tabelas para contabilização da frequência de imperfeições e palhetas de análise de tonalidades. Atribuiu-se, então, que a composição de maior qualidade visual corresponde àquela que apresentou menor quantidade de imperfeições superficiais e regularidade tonal.

\subsection{Contabilização dos problemas superficiais}

A Tab. 2 apresenta os problemas superficiais encontrados nos corpos de prova com adição de ossos bovinos.

Tabela 2 - Problemas superficiais identificados na cerâmica com ossos.

\begin{tabular}{|c|c|c|c|c|c|c|c|c|c|c|c|c|c|}
\hline & 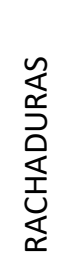 & 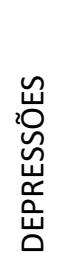 & 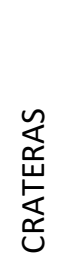 & $\begin{array}{l}\text { 足 } \\
\text { İ } \\
\text { ○े }\end{array}$ & 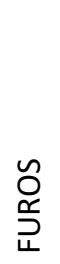 & $\frac{n}{\frac{n}{E}}$ & 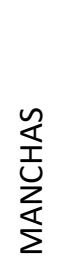 & 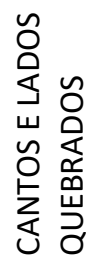 & 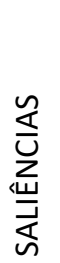 & 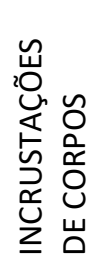 & 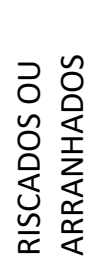 & $\begin{array}{l}\stackrel{\leftarrow}{5} \\
\stackrel{\rho}{\circ}\end{array}$ & 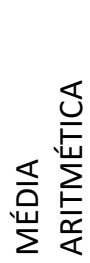 \\
\hline OB30/1 & 0 & 0 & 0 & 0 & 0 & 0 & 0 & 1 & 0 & 0 & 0 & 1 & \multirow{3}{*}{2,6} \\
\hline OB30/2 & 0 & 0 & 0 & 0 & 0 & 0 & 0 & 2 & 0 & 0 & 0 & 2 & \\
\hline OB30/3 & 0 & 1 & 0 & 0 & 0 & 0 & 0 & 4 & 0 & 0 & 0 & 5 & \\
\hline OB35/1 & 1 & 0 & 0 & 0 & 0 & 0 & 0 & 3 & 1 & 0 & 0 & 5 & \multirow{3}{*}{3,3} \\
\hline OB35/2 & 0 & 0 & 0 & 0 & 0 & 0 & 0 & 2 & 1 & 0 & 0 & 3 & \\
\hline OB35/3 & 0 & 0 & 0 & 0 & 0 & 0 & 0 & 2 & 0 & 0 & 0 & 2 & \\
\hline OB40/1 & 0 & 1 & 0 & 0 & 0 & 0 & 0 & 3 & 1 & 0 & 0 & 5 & \multirow{3}{*}{5,3} \\
\hline OB40/2 & 0 & 0 & 0 & 0 & 1 & 0 & 0 & 4 & 1 & 0 & 0 & 6 & \\
\hline OB40/3 & 0 & 0 & 0 & 0 & 0 & 0 & 0 & 4 & 1 & 0 & 0 & 5 & \\
\hline OB45/1 & 0 & 0 & 0 & 0 & 0 & 0 & 0 & 4 & 0 & 0 & 0 & 4 & \multirow{3}{*}{6} \\
\hline OB45/2 & 0 & 0 & 1 & 0 & 0 & 0 & 0 & 5 & 0 & 0 & 0 & 6 & \\
\hline OB45/3 & 0 & 1 & 1 & 0 & 0 & 0 & 0 & 6 & 0 & 0 & 0 & 8 & \\
\hline OB50/1 & 1 & 0 & 0 & 0 & 0 & 0 & 0 & 5 & 0 & 0 & 0 & 6 & \multirow{3}{*}{5,3} \\
\hline OB50/2 & 0 & 0 & 0 & 0 & 0 & 0 & 0 & 5 & 1 & 0 & 0 & 6 & \\
\hline OB50/3 & 0 & 1 & 0 & 0 & 0 & 0 & 0 & 3 & 0 & 0 & 0 & 4 & \\
\hline OB55/1 & 1 & 0 & 0 & 0 & 0 & 0 & 0 & 3 & 1 & 0 & 0 & 5 & \multirow{3}{*}{5} \\
\hline OB55/2 & 0 & 1 & 0 & 0 & 0 & 0 & 0 & 3 & 1 & 0 & 0 & 5 & \\
\hline OB55/3 & 0 & 1 & 0 & 0 & 0 & 0 & 0 & 4 & 0 & 0 & 0 & 5 & \\
\hline TOTAL & 3 & 6 & 2 & 0 & 1 & 0 & 0 & 63 & 8 & 0 & 0 & 83 & \\
\hline
\end{tabular}

Fonte: Elaborado pelo autor, com base na pesquisa realizada.

Com um total de 83 problemas, os corpos cerâmicos não apresentaram bolhas, pintas, manchas, incrustações de corpos estranhos, riscados ou arranhados, mas os cantos quebrados foram apontados como o problema superficial mais frequente. Já 
em relação às porcentagens residuais, a quantidade de defeitos e imperfeições aumentou gradualmente nas composições de 30\%, 35\%, $40 \%$ até $45 \%$ de resíduos. Nas demais composições, observou-se uma queda significativa neste número.

Com base nestes dados, as cerâmicas com 30\% e 35\% de ossos apresentaram os melhores resultados quanto à contabilização de problemas superficiais.

Já na Tabela 3, encontram-se problemas dos corpos com fino de rochas. Com mais imperfeições (204), apresentou 64 manchas e 73 cantos quebrados, sem bolhas e incrustações. Em ambos os resíduos, os cantos quebrados são passíveis de minimização quando em um processamento mais criterioso, de manuseio cuidadoso, contudo a grande quantidade de manchas afeta diretamente na estética do produto.

Tabela 3 - Problemas superficiais identificados na cerâmica com fino de rochas.

\begin{tabular}{|c|c|c|c|c|c|c|c|c|c|c|c|c|c|}
\hline & 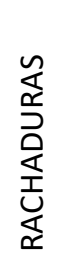 & 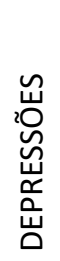 & 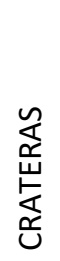 & $\begin{array}{l}\text { ñ } \\
\text { İ } \\
\text { ○े }\end{array}$ & 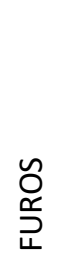 & $\frac{n}{\frac{E}{E}}$ & 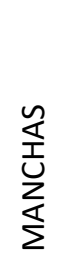 & 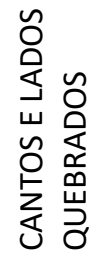 & 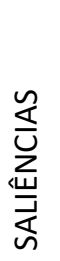 & 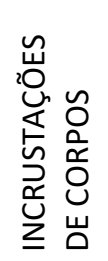 & 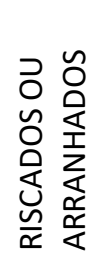 & $\begin{array}{l}\stackrel{1}{\leqslant} \\
\stackrel{6}{\circ}\end{array}$ & 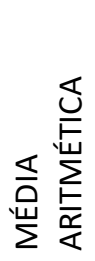 \\
\hline R30/1 & 0 & 0 & 0 & 0 & 0 & 1 & 1 & 4 & 1 & 0 & 0 & 7 & \\
\hline $\mathrm{R} 30 / 2$ & 0 & 0 & 0 & 0 & 0 & 0 & 1 & 2 & 0 & 0 & 0 & 3 & 4,6 \\
\hline R30/3 & 0 & 0 & 1 & 0 & 0 & 0 & 1 & 2 & 0 & 0 & 0 & 4 & \\
\hline R35/1 & 0 & 1 & 0 & 0 & 0 & 0 & 3 & 1 & 1 & 0 & 0 & 6 & \\
\hline R35/2 & 0 & 0 & 0 & 0 & 0 & 0 & 4 & 3 & 1 & 0 & 0 & 8 & 7,6 \\
\hline R35/3 & 0 & 1 & 0 & 0 & 0 & 0 & 4 & 4 & 0 & 0 & 0 & 9 & \\
\hline $\mathrm{R} 40 / 1$ & 0 & 2 & 0 & 0 & 0 & 0 & 4 & 3 & 0 & 0 & 0 & 9 & \\
\hline $\mathrm{R} 40 / 2$ & 0 & 2 & 0 & 0 & 0 & 0 & 4 & 4 & 1 & 0 & 0 & 11 & 10 \\
\hline $\mathrm{R} 40 / 3$ & 0 & 0 & 0 & 0 & 2 & 0 & 4 & 3 & 1 & 0 & 0 & 10 & \\
\hline $\mathrm{R} 45 / 1$ & 3 & 1 & 0 & 0 & 0 & 0 & 3 & 4 & 1 & 0 & 0 & 12 & \\
\hline $\mathrm{R} 45 / 2$ & 1 & 2 & 1 & 0 & 0 & 0 & 4 & 4 & 1 & 0 & 2 & 15 & 13 \\
\hline $\mathrm{R} 45 / 3$ & 0 & 0 & 0 & 0 & 0 & 0 & 5 & 6 & 0 & 0 & 1 & 12 & \\
\hline $\mathrm{R} 50 / 1$ & 4 & 1 & 1 & 0 & 0 & 0 & 4 & 7 & 0 & 0 & 0 & 17 & \\
\hline $\mathrm{R} 50 / 2$ & 3 & 0 & 3 & 0 & 0 & 0 & 5 & 6 & 1 & 0 & 3 & 21 & 18,3 \\
\hline $\mathrm{R} 50 / 3$ & 3 & 0 & 0 & 0 & 1 & 0 & 5 & 5 & 0 & 0 & 3 & 17 & \\
\hline R55/1 & 0 & 0 & 0 & 0 & 1 & 7 & 6 & 5 & 2 & 0 & 2 & 23 & \\
\hline $\mathrm{R} 55 / 2$ & 0 & 0 & 0 & 0 & 1 & 2 & 6 & 10 & 1 & 0 & 0 & 20 & 21,5 \\
\hline TOTAL & 14 & 10 & 6 & 0 & 5 & 10 & 64 & 73 & 11 & 0 & 11 & 204 & \\
\hline
\end{tabular}

Fonte: Elaborado pelo autor, com base na pesquisa realizada.

Acredita-se que os corpos com fino de rochas apresentaram um número elevado de problemas devido à temperatura da sinterização. Segundo conclusões da dissertação de Prado (2014), que estudou o comportamento da cerâmica vermelha com rochas ornamentais em variadas temperaturas de queima, as peças devem ser sinterizadas a $1150^{\circ} \mathrm{C}$ para maior resistência mecânica, pois em temperatura de queima mais elevada, maior aglutinação das partículas e, portanto, torna-se mais resistente. Assim, acredita-se que testes futuros com temperaturas mais elevadas possam enumerar quantidade menor de problemas superficiais do material.

Quanto aos percentuais de incorporação de resíduos, houve um crescimento gradual de imperfeições. Quanto maior a quantidade de resíduos, mais problemas superficiais. Identificou-se a menor média de 4,6 problemas em composições de $30 \%$, 
e a maior com 21,5 problemas em $55 \%$ de resíduos. Assim, cerâmicas com $30 \%$ e 35\% dos dois resíduos apresentaram melhores resultados na contabilização de problemas.

\subsection{Diferenças de tonalidades}

As diferenças de tonalidade consistem em outra característica estética avaliada. Sua relevância se dá devido à previsão tonal do material para aplicação em produtos. Assim, a Figura 2 mostra a superfície dos corpos sinterizados com ossos. Foi escolhido 1 corpo de prova de cada mistura de modo aleatório para representar a porcentagem.

Tonalidades da porcelana de ossos

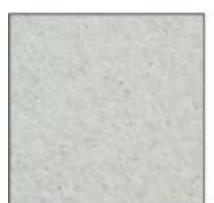

Triaxial

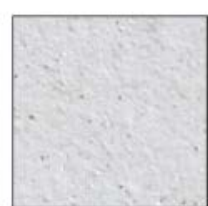

$30 \%$

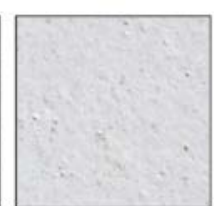

$35 \%$

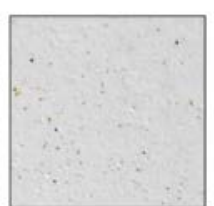

$40 \%$

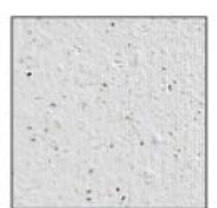

$45 \%$

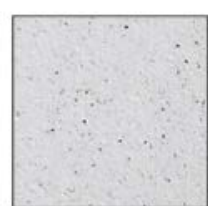

$50 \%$

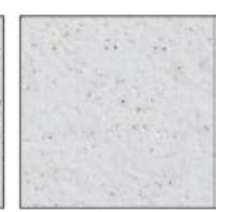

$55 \%$

Figura 2 - Tonalidades da cerâmica com adição de ossos.

Fonte: Elaborado pelo autor, com base na pesquisa realizada.

Foram obtidas peças mais alvas às triaxiais, que são na cor bege. A cerâmica com ossos apresentou cor branca, com pequenos pontos escuros. Segundo Mayahara, Gouveia e Toffoli (2007), a cor do produto é influenciada pelo tratamento anterior do resíduo, por isso deve ser beneficiado adequadamente. Para os ossos, deve-se realizar a calcinação para eliminação dos restos de sangue e carne, retirando o óxido de ferro capaz de proporcionar cor escura. Os mesmos autores citam que os ossos podem apresentar diferentes cores após a calcinação - branco, preto e vermelho-, contudo não exercem influência no resultado final devido à mudança de fase cristalina do material, o que explica a cor apresentada na Figura 3, que mostra a variação tonal quanto às porcentagens residuais propostas e sua relação com o tempo.

Um dia após a sinterização

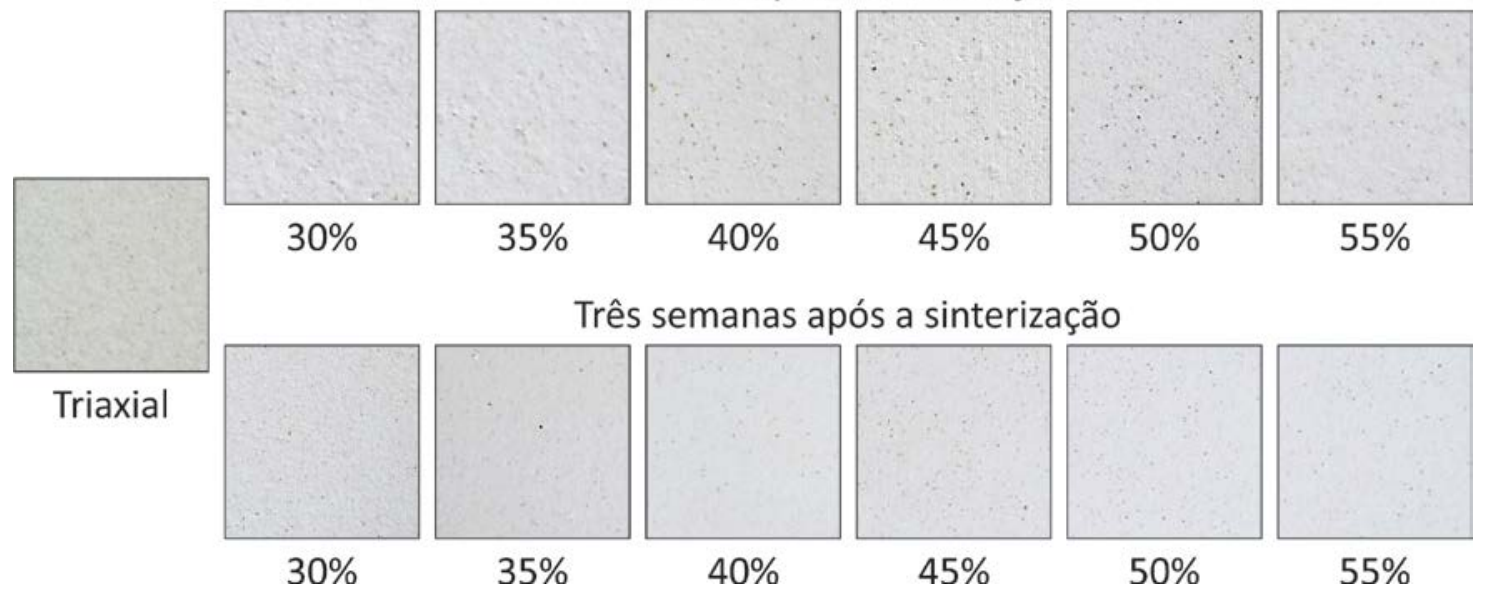

Figura 3 - Tonalidades da cerâmica com adição de ossos em relação ao tempo. Fonte: Elaborado pelo autor, com base na pesquisa realizada.

Todos os corpos de prova apresentaram uma similaridade tonal, sem diferenças significativas entre composições com menores ou maiores quantidades de ossos. Houve, ainda, regularidade quanto ao tempo. As peças não escureceram nem 
clarearam de modo significativo com o passar das semanas, mantendo a cor e o tom inicial. Dessa maneira, torna-se mais fácil prever o resultado final da cor.

Já para as cerâmicas produzidas com fino de rochas ornamentais, a análise de tonalidade apresentou resultados bem diferentes. A Figura 4 mostra a superfície dos corpos de prova com este material após 3 semanas da sinterização.

Tonalidades da cerâmica branca com rochas (3 sem.)

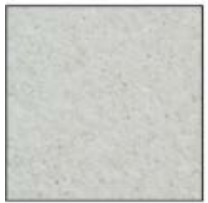

Triaxial

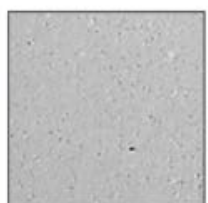

$30 \%$

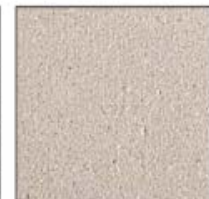

$35 \%$

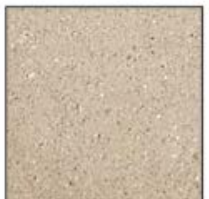

$40 \%$

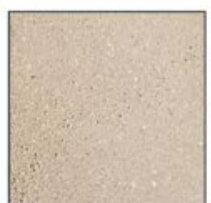

$45 \%$

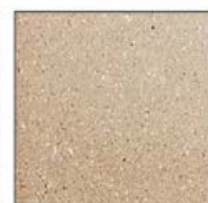

$50 \%$

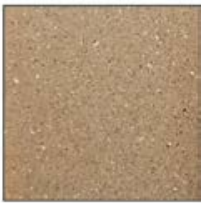

$55 \%$

Figura 4 - Tonalidades da cerâmica com adição de fino de rochas ornamentais.

Fonte: Elaborado pelo autor, com base na pesquisa realizada.

Os corpos de prova apresentaram uma tonalidade mais escura em relação à cerâmica triaxial. A cartela de cores obtidas foi apresentada como resultado final devido à uma significativa variação de tonalidades apresentada entre o período após a conformação e algumas semanas seguintes. A Figura 5 mostra a relação entre as composições de fino, seu comportamento com o tempo e os percentuais residuais.

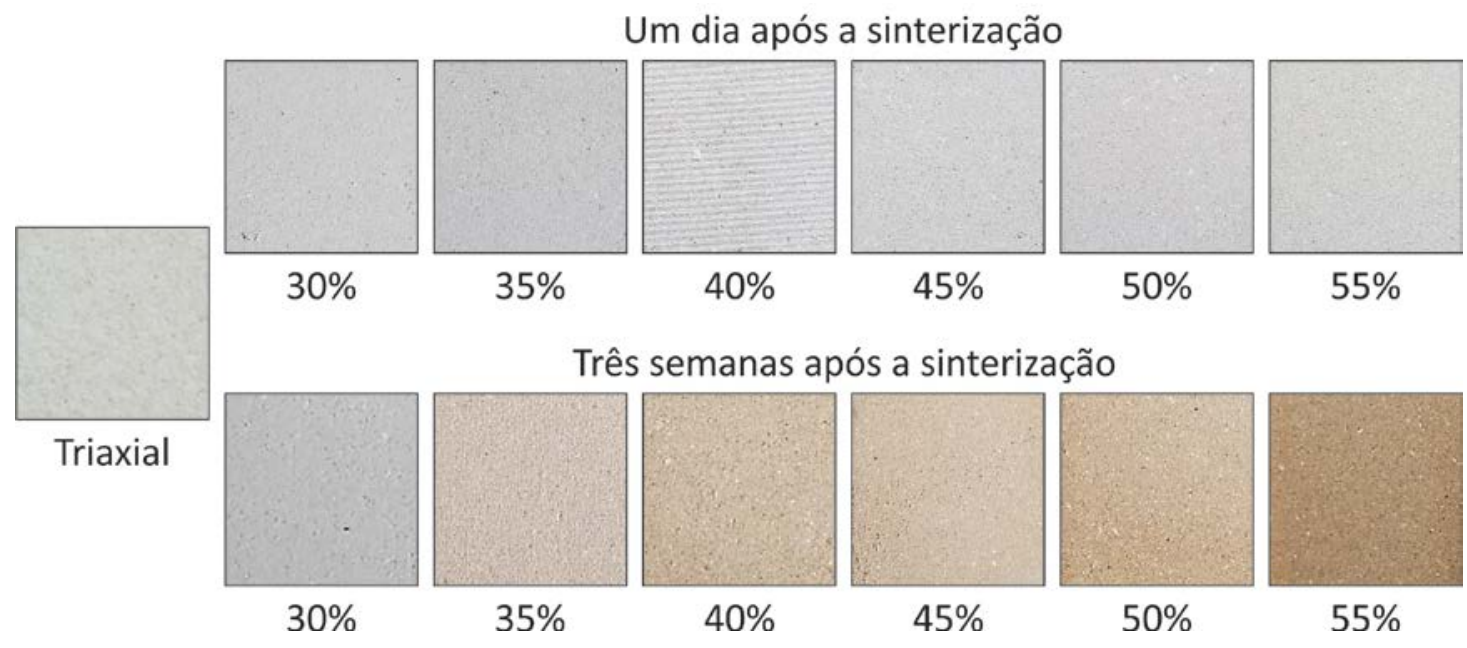

Figura 5 - Tonalidades da cerâmica com adição de fino de rochas ornamentais em relação ao tempo.

Fonte: Elaborado pelo autor, com base na pesquisa realizada.

Observou-se que à medida que mais resíduo foi acrescentado, mais escuro se tornou o corpo cerâmico, havendo significativa diferença entre composições. Também foi observado que houve uma diferença de tonalidade nas peças com fino de rochas ao longo das semanas, tornando suas superfícies cada vez mais escuras. Para a comprovação deste fenômeno, alguns corpos de prova foram separados e cobertos por fita adesiva em apenas uma área por dez dias. O resultado encontra-se na Figura 6. A "Cor A" foi a região sem a fita, exposta diretamente ao ar e a "Cor B" ficou coberta. Portanto, o registro mostrou uma tonalidade sutilmente mais clara na "Cor B", comprovando a diferença tonal ao longo das semanas. 

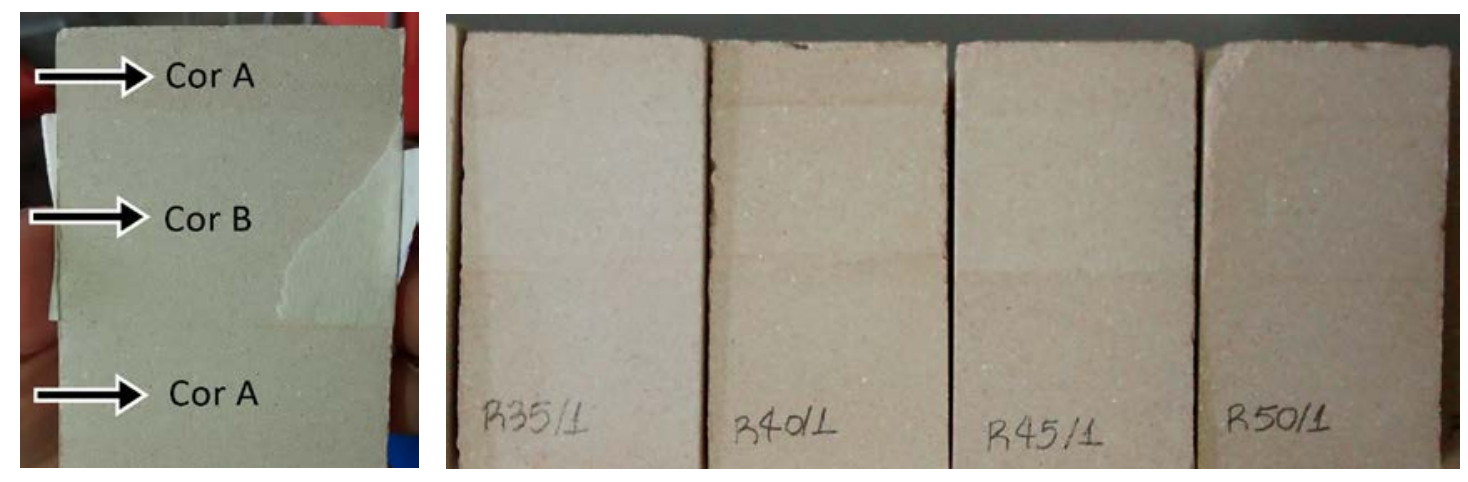

Figura 6 - Diferenças de tonalidades.

Fonte: Elaborado pelo autor, com base na pesquisa realizada.

As cores assemelharam-se a tons de caramelo, com leve roseado, possibilitando algumas hipóteses para o fenômeno: é possível que exista mais óxido de ferro que na cerâmica triaxial e daquela com ossos; talvez exista outro mineral na rocha que possa gerar esta tonalidade; ou, ainda, alguns componentes geradores de cor podem ter se agregado durante o período que o fino foi exposto às intempéries na área de corte das marcenarias; ou mesmo uma causa desconhecida.

Acredita-se que o beneficiamento do resíduo tenha influenciado na cor, por não ter passado por tratamento térmico prévio, como foi realizado com ossos. Mayahara, Gouveia e Toffoli (2007) explicam que o tratamento anterior do resíduo influencia diretamente nos resultados superficiais. Dessa maneira, observou-se que este material apresenta colorações diferentes, de comportamento não constante. Contudo, para afirmação do motivo pelo qual este material apresentou estas tonalidades, faz-se necessário um estudo complementar com análise química do material. Assim, fica como uma sugestão de estudo posterior.

Retomando-se à cor da cerâmica, concluiu-se que o material apresentou tons terrosos sem precisão. É importante ressaltar, também, que existe mais uma variável que interfere no resultado final: a demanda. As rochas que passam pelo corte nas marmorarias não são as mesmas, pois são beneficiadas à medida que os pedidos são realizados pelos clientes. Portanto, o material acumulado no tanque - e chamado de fino - pode ser de cores variadas conforme a demanda diária do tipo de rocha. Assim não há como prever com exatidão a cor final com este resíduo, o que ainda sim não desqualifica o material, uma vez que pode ser utilizado como produto rústico e pode ganhar um acabamento, como a vitrificação com óxidos em tonalidades variadas.

\section{CONCLUSÕES}

Após a análise e discussão dos resultados obtidos, observou-se que as composições com menores quantidades dos dois tipos de resíduos - 30\% e 35\% apresentam uma média menor de imperfeições. Conclui-se, então que estas misturas apresentaram os melhores resultados com os dois resíduos.

Os corpos de prova de cerâmica branca com ossos bovinos apresentaram coloração branca regular, mais alva que a triaxial, sem variação significativa quanto ao percentual de resíduos e quanto ao tempo, o que propõe a utilização em produtos que necessitem de qualidade superficial, coloração branca e estabilidade de cor.

Já no fino de rochas, os corpos apresentaram tonalidades irregulares mais escuras que as triaxiais, em tons de caramelo, com variação quanto ao percentual e 
quanto ao tempo. Ou seja, corpos cerâmicos com maior quantidade de resíduos apresentaram uma coloração mais escura e tornaram-se ainda mais intensas ao longo do tempo. Com esta instabilidade de cor, torna-se inviável a previsão de coloração em um produto, a menos que o objetivo seja que o produto apresente aspecto visual rústico ou que não apresente a exigência de tonalidade específica. Uma solução para melhoramento da qualidade seria um acabamento posterior como a vitrificação, que proporciona estabilidade de cor ao material e também aumento na resistência.

Ainda que a pesquisa demonstre que os melhores resultados obtidos na análise foram provenientes das cerâmicas com os menores percentuais de resíduos, a substituição de $30 \%$ de matéria-prima por sobras de outros processos produtivos já representa ganhos à indústria, com economia de gastos, de extração de matéria-prima e diferenciação na estética dos produtos que utilizarem os materiais estudados.

\section{AGRADECIMENTOS}

Este artigo foi desenvolvido com a ajuda de algumas pessoas e instituições, por isso é necessário agradecer à Coordenação de Aperfeiçoamento de Pessoal de Nível Superior (CAPES), ao Conselho Nacional de Desenvolvimento Científico e Tecnológico (CNPq), à Fundação de Amparo à Pesquisa e Desenvolvimento Científico do Maranhão (FAPEMA) e ao Laboratório de Cerâmica do Curso de Design, localizado na Universidade Federal do Maranhão, além da bolsista Railde de Paula Diniz.

\section{REFERÊNCIAS}

ABNT. NBR 10004: Associação Brasileira de Normas Técnicas - Classificação de resíduos sólidos, Rio de Janeiro, 2004.

ABNT. NBR 13818: Associação Brasileira de Normas Técnicas - Placas cerâmicas para revestimento - especificação e métodos de ensaio, Rio de Janeiro, 1997.

ALATRISTA, Gerardo Augusto Vera. Preparação e estabilização de uma suspensão cerâmica de porcelana de ossos. 2008. 88 f. Tese (Mestrado em Engenharia) Universidade de São Paulo, Programa de Pós-graduação em Engenharia.

ASKLAND, Donald R; WRIGHT, W. Ciência e engenharia dos materiais. São Paulo: Ed. Cengage Learning, 2014.

BABISK, M. P; et. al. Incorporação de resíduo de quartzitos em cerâmica vermelha. Revista Holos. Rio Grande do Norte, Ano 28, Vol 6, p. 169-177, 2012.

BRAGANÇA, S. R.; BERGMANN, C. P. Produção de porcelana de ossos e caracterização de suas propriedades técnicas. Revista Cerâmica. São Paulo, Vol. 52, № 322, Abril/ Junho, p. 205-212, 2006.

BRASIL. Constituição de 1988. BRASIL. Lei no 12.305, de 2 de agosto de 2010.

FRANGELLA, L.M.N; CASTRO, N. F. Aproveitamento de rejeitos gerados no beneficiamento de rochas ornamentais. In: XXIII Simpósio de Geologia do Nordeste. Fortaleza: CETEM/ MCT, 2009.

IBGE, BRASIL. Indicadores IBGE: Estatística da Produção Pecuária Setembro de 2013. 2013. Disponível na internet por http em: <http://www.ibge.gov.br/home/estatistica/ 
indicadores/agropec uaria/producaoagropecuaria/abate-leite-couroovos_201302_publ_completa.pdf>. Acesso em: 20 jul. 2014.

MAYAHARA, R. Y.; GOUVEIA, D.; TOFFOLI, S. M. Obtenção e caracterização de cinza de ossos bovinos visando à fabricação de porcelana de ossos - bone china. Revista Cerâmica. São Paulo, Vol. 53, №. 327, p. 234-239, Setembro, 2007.

MELLO, I.S.C.; et. al. Atlas de matérias-primas minerais cerâmicas do nordeste brasileiro. São Paulo: CPRM, 2011.

MENDES FILHO, Antônio Alves. Síntese e caracterização de hidroxiapatita e compósitos à partir de matéria-prima reciclada. 2006. $181 \mathrm{f}$. Tese (Doutorado em Engenharia de Materiais) - Universidade Federal de Ouro Preto, Programa de Pósgraduação em Engenharia de Materiais.

MOREIRA, P.B.W. et. al. Caracterização das propriedades físico-químicas das argilas utilizadas em indústrias de cerâmica vermelha na Baixada Maranhense. In: VII Congresso Nacional de Engenharia Mecânica, 31 de julho a 3 de agosto. São Luís, 2012. NORTON, Frederick Harwood. Introdução à tecnologia cerâmica. Tradução: Jefferson Vieira de Souza. São Paulo: Edgard Blücher, 1973.

PRADO, ARTIDÔNIO DANTAS. Efeito da incorporação de resíduo industrial (chamote, mármore e granito) para produção de revestimento cerâmico. 2014. 62 f. Dissertação (Mestrado em Engenharia de Materiais) - Instituto Federal do Maranhão, Programa de Pós-Graduação em Engenharia de Materiais.

RIGO, E. C. S.; GEHRKE, S. A.; CARBONARI, M. Síntese e caracterização de hidroxiapatita obtida pelo método de precipitação. Revista Dental Press de

Periodontia e Implantologia. Maringá, Vol. 1, № 3, p. 39-50, Jul/ Set, 2007.

SANTOS, Pérsio de Sousa. Tecnologia de argilas, aplicada às argilas brasileiras. São Paulo: Edgard Blücher, 1975.

SHACKELFORD, James F. Introdução à Ciência dos Materiais para Engenheiros. Tradução: Daniel Vieira. São Paulo: Pearson Prentice Hall, 2008.

SOUSA, José Gonçalves de. Análise ambiental do processo de extração e beneficiamento de rochas ornamentais com vistas a uma produção mais limpa: aplicação em Cachoeiro de Itapemirim - ES. 2007. 30 f. Trabalho de conclusão de curso (Especialização em Análise Ambiental) - Universidade Federal de Juiz de Fora.

SOUZA, V.C; SOUZA, J.C.; ROLIM FILHO, J.L. Diagnóstico do setor de rochas ornamentaise de revestimentos do Estado de Pernambuco. Estudos geológicos, Pernambuco, volume 8, 2008.

TEIXEIRA, Anthony Francis Nunes; MELO, Larize Bezerra de; OLIVEIRA, Narla Sathler Musse de, Rochas ornamentais: o desenvolvimento econômico e suas relações com a sociedade brasileira e norte-riograndense. In: VII CONNEPI, Congresso Norte Nordeste de Pesquisa e Inovação. 2012, Palmas, 2012. 